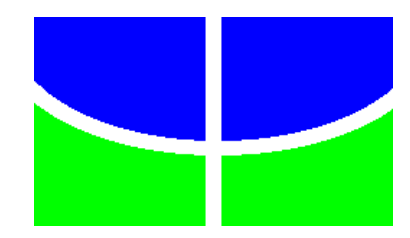

UNIVERSIDADE DE BRASÍLIA

Centro de Excelência em Turismo

Pós-Graduação Lato Sensu

Curso de Especialização em Qualidade em Alimentos

\title{
AVALIAÇÃO NUTRICIONAL DOS EMPRATADOS DE UMA REDE DE FAST FOOD DO DISTRITO FEDERAL
}

\author{
Christiane Lopes Vieira Assunção
}

Orientadora: Dra. Rita de Cássia Akutsu

Monografia apresentada ao Centro de Excelência em Turismo - UNB como requisito parcial para obtenção de título de Especialista em Qualidade em Alimentos

Brasília, 2009 
Assunção, Christiane Lopes Vieira.

Avaliação dos empratados de uma rede de fast food no DF / Christiane Assunção. - Brasília, 2009.

34 páginas

Monografia (especialização) - Universidade de Brasília, Centro de Excelência em Turismo, 2009.

Orientadora: Prof ${ }^{a} D^{\text {ra }}$ Rita Akutsu.

1. Alimentos. 2. Alimentação fora de casa. 3. Fast Food .4 PAT. 


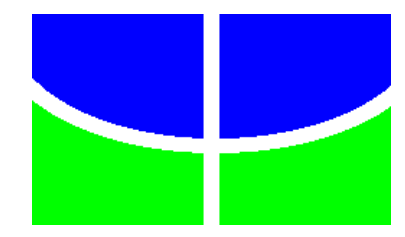

UNIVERSIDADE DE BRASÍLIA

Centro de Excelência em Turismo

Pós-Graduação Lato Sensu

Curso de Especialização em Qualidade em Alimentos

\title{
CHRISTIANE LOPES VIEIRA ASSUNÇÃO
}

\section{AVALIAÇÃO NUTRICIONAL DOS EMPRATADOS DE UMA REDE DE FAST FOOD DO DISTRITO FEDERAL}

\begin{abstract}
Monografia apresentada ao Centro de Excelência em Turismo - CET, da Universidade de Brasília, como requisito parcial à obtenção do grau de Especialista em Qualidade em Alimentos.
\end{abstract}

Aprovado em:

Prof $^{a}$ Dr $^{\mathrm{a}}$. Rita de Cássia Akutsu

Prof ${ }^{a}$ Orientadora

Prof $^{\mathrm{a}} \mathrm{Dr}^{\mathrm{a}}$. Karin Eleonora Sávio de Oliveira

Prof $^{a}$ Dr $^{\mathrm{a}}$. Raquel Braz Assunção Botelho

BRASÍLIA - DF

2009 
Dedico este trabalho a minha família que é meu porto seguro nas horas mais difíceis, principalmente ao meu marido pelo apoio incondicional. 


\section{AGRADECIMENTOS}

Agradeço a Deus que me conduziu até aqui e por permitir mais esta conquista.

À minha orientadora Professora Dra. Rita de Cássia Akutsu pela força, sabedoria e dedicação durante a realização deste trabalho.

Aos funcionários da secretária do Centro de Excelência em Turismo (CET) pelo o desempenho de suas atividades operacionais prestados, em consonância com os interesses dos alunos.

Às pessoas que encontrei no meu caminho e me ensinaram a viver. 


\section{RESUMO}

Assunção, Christiane Lopes Vieira. Avaliação dos Empratados de uma Rede de fast food do Distrito Federal. 2009. 34 p. Monografia - Programa de Pós-Graduação em Qualidade em Alimentos - Universidade de Brasília. Centro de Excelência em Turismo. Brasília, 2009.

Atualmente o tempo de deslocamentos e a maior jornada de trabalho impedem que muitas pessoas realizem suas refeições em casa. Vale lembrar também que no final do século $\mathrm{XX}$ a força de trabalho feminino fora de casa aumentou interferindo no provimento de refeições caseiras aos demais membros da família. Com a diversidade de fatores que refletem o crescimento das refeições fora do lar os fast foods são os mais optados pelos consumidores. Estes restaurantes passaram a introduzir nos seus cardápios empratados com alimentos que lembram as refeições preparadas em casa no horário do almoço como: arroz, feijão, carnes, aves, peixes, saladas, purês, farofa, macarrão e sobremesas. Em virtude do exposto este estudo objetivou avaliar a composição nutricional dos empratados servidos em uma rede de fast food do Distrito Federal. Os objetivos específicos englobam a análise quantitativa dos Macronutrientes (carboidratos, proteínas e lipídeos), do micronutriente sódio e das fibras contidas nestas refeições e comparar esses dados com os valores estabelecidos pelo Programa de Alimentação do Trabalhador -PAT, já que a maiorias dos consumidores no horário do almoço são trabalhadores. A pesquisa é um estudo do tipo transversal exploratório. Para a coleta de dados foram analisados 10 pratos considerados padrões básicos, compostos por dois acompanhamentos (arroz e feijão), duas guarnições (farofa e salada) e uma preparação protéica. Para base de cálculo foi usado o VET diário de 2000 calorias com percentual de 55 a $75 \%$ para o Carboidratos, 10 a 15\% para as proteínas e 15 a 30\% para as gorduras, o sódio $\leq 2400 \mathrm{mg} / \mathrm{d}$ e fibras $>25 \mathrm{~g} / \mathrm{d}$. Quanto a quantidade de energia dos empratados os valores encontrados encontram-se dentro dos parâmetros estabelecido pelo PAT. Para o carboidrato todas as preparações apresentaram abaixo da recomendação. A maioria das preparações os valores encontrados para a proteína dietética ficaram dentro da recomendação, os valores encontrados nos empratados para os lipídeos e o sódio foram elevados já as fibras contribuíram para os valores dentro da recomendação. Refeições ricas em lipídeos e sódio se consumidos por um período prolongado e associado ao sedentarismo causam grandes danos ao coração e ao fígado além de propiciar doenças crônicas não transmissíveis. Sugere-se a elaboração e implantação das fichas técnicas de preparação e a busca por receitas tradicionais, onde não há adição de ingredientes que tornam a preparação nutricionalmente inadequada. Palavras-chave: Alimentos, alimentação fora de casa, fast food, PAT, nutrientes, doenças. 


\begin{abstract}
Assunção, Christiane Lopes Vieira. Avaliação dos Empratados de uma Rede de fast food do Distrito Federal. 2009. 34 p. Monografia - Programa de Pós-Graduação em Qualidade em Alimentos - Universidade de Brasília. Centro de Excelência em Turismo. Brasília, 2009.
\end{abstract}




\section{SUMÁRIO}

Resumo.

Abstract

I. Introdução

II. Objetivos

III. Revisão Bibliográfica

IV. Metodologia

V. Resultados e discussão

VI. Conclusão.

VII Referências.

Apêndice 


\section{INTRODUÇÃO}

Durante o crescimento histórico, a alimentação marcou etapas importantes no processo evolutivo do homem. Inicialmente, o homem limitava-se à caça, à pesca, à coleta de vegetais e a outros materiais biológicos. Posteriormente, aconteceu uma grande mudança na evolução cultural, com processo de adaptação de plantas e de animais, que permitiu ao homem controlar o meio ambiente e a técnica, e depois passar a planejar a produção de alimentos que se destinavam não apenas à satisfação das necessidades da comunidade relacionada à fome, mas também à produção de excedentes comercializáveis (CUPPARI, 2002).

Por outro lado, os esforços desenvolvidos pelo homem para enfrentar as situações adversas resultaram na formação de hábitos alimentares particulares a cada população (DAMASCENO et al., 2002).

A fome e a sede são, então, formuladas e saciadas em termos culturais, sociais e históricos. O quê se come, com quem se come, quando, como e onde se come, as prescrições e proscrições alimentares são definidas pela cultura. É assim que as práticas, classificações e representações da alimentação indicam o status de um indivíduo em uma sociedade, bem como a cozinha de um grupo social, agindo na conformação da relação de pertencimento de seus membros, expressa sua identidade. A comida pode, então, ser tomada como linguagem, como texto cultural que fala do corpo, da família, do trabalho, de relações sociais, de visões de mundo (MENASCHE; MARQUES; ZANETTI, 2008).

Atualmente as dificuldades impostas pelo tempo de deslocamentos e a maior jornada de trabalho impedem que muitas de pessoas realizem suas refeições em família com isso dificultando a relação de troca e identidade. (CARDOSO; SOUSA; SANTOS, 2005).

Há que lembrar que no final do século XX a força de trabalho feminino alimentou a falta de mulheres nos lares, interferindo no provimento de refeições caseiras aos demais membros da família, principalmente o desjejum e o almoço (COELHO, 2001). Isso leva a duas situações distintas, ou as pessoas optam pela omissão dessas refeições, ou as substituem por alimentos altamente calóricos, como é o caso dos alimentos servidos no fast foods (RIAL, 2004).

Com a diversidade de fatores que refletem o crescimento das refeições fora do lar, os restaurantes de comidas prontas e ou rápidas, denominados fast foods, são os mais optados pelos consumidores. Tais refeições devem estar dentro dos padrões de higiene e adequação de nutrientes para garantir segurança ao indivíduo (AKUTSU et al., 2005). 
Embora estes estabelecimentos devam oferecer refeições seguras e adequadas nutricionalmente, não há garantia de que o façam em virtude da legislação e físcalização serem deficientes, outro ponto a ser destacado é a despreocupação por parte da população que não tem tempo para analisar e verificar o que estão comendo obtendo assim confiança no serviço prestado pelo restaurante (NERI; CURTI; FISBERG, 2006).

Em virtude do exposto este estudo tem como objetivo geral avaliar a composição nutricional dos empratados servidos em uma rede de fast food do Distrito Federal. Os objetivos específicos englobam a análise quantitativa dos Macronutrientes (carboidratos, proteínas e lipídeos), do micronutriente sódio e das fibras contidas nestas refeições além de comparar esses dados com os valores estabelecidos pelo Programa de Alimentação do Trabalhador-PAT.

Para melhor estruturar a compreensão deste trabalho, o mesmo foi dividido na presente introdução que contêm um breve histórico sobre a alimentação, principalmente em relação ao consumo de alimentos fora do lar; apresentando ainda os objetivos geral e específicos; revisão bibliográfica, destacando a importância da alimentação para o crescimento e desenvolvimento do indivíduo no contexto da manutenção da vida, alimentação fora de casa e sobre os parâmetros nutricionais do PAT; materiais e métodos utilizados neste trabalho; resultados obtidos; discussão e conclusão. 


\section{REVISÃO DE LITERATURA}

\subsection{O PAPEL DA ALIMENTAÇÃO PARA $O$ CRESCIMENTO E DESENVOLVIMENTO.}

Na segunda metade do século XX, a sociedade passou por um intenso processo de mudança, sendo uma delas caracterizada pela transição nutricional, que se dá pela passagem de um estágio bem primitivo, simbolizado pela ocorrência de graves carências nutricionais (kwashiokor, marasmo nutricional, hipovitaminose A, escorbuto, beribéri, raquitismo, osteomalácia, pelagra), para um outro estágio em que predominam as doenças crônicas nãotransmissíveis (obesidade e diabetes). Por conta dessas mudanças, houve modificação na estrutura da base demográfica da pirâmide nutricional, com a queda da mortalidade por doenças facilmente evitáveis e curáveis, passando a um prolongamento da vida. Outra conseqüência foi a modificação dos hábitos alimentares e a redução das atividades físicas, com isso ocasionou um ganho de peso excessivo e o predomínio marcante das doenças crônicas não-transmissíveis (KAC; SICHIERI; GIGANTE, 2007).

Nessas circunstâncias atualmente, e ainda por todo este século, muitos estudos continuam a demonstrar a importância de hábitos alimentares saudáveis e a prática de atividade física para manter a saúde. Cabe destacar que a introdução de alimentos que tenham nutrientes indispensáveis ou essenciais são capazes de prevenir os problemas nutricionais e evitar doenças (SHILS et al., 2003).

Mas é preciso destacar que a qualidade de vida que está ligado à saúde e ao bemestar de uma população depende não só da alimentação adequada mais de vários fatores, como emprego e renda, educação básica, acesso a bons serviços de saúde, saneamento básico, habitação, transporte de boa qualidade, entre outros. E o conceito de qualidade de vida varia de sociedade para sociedade, de acordo com a cultura de cada uma (DEPS, 1993).

Vale lembrar ainda que Canesqui (2007) diz que a nutrição, na história da humanidade, é mais do que prover energia, ela abarca tanto as necessidades físicas e corporais quanto à dimensão imaginária dos homens em relação aos alimentos. A comida não é ingerida apenas por razões nutricionais, apesar de ela preencher necessidades vitais e biológicas fundamentais que garantem a própria vida e sobrevivência dos seres humanos ela combina uma multiplicidade de fatores e a interdependência entre o homem biológico, o homem social e o cultural. Cuppari (2002) expõe que nutrição é a ciência que estuda os alimentos, seus nutrientes, bem como sua ação, interação e balanço em relação a doença, além dos processos 
pelos quais o organismo ingere, absorve, transforma, utiliza e excreta os nutrientes. Uma alimentação variada refere-se à seleção de alimentos dos diferentes grupos.

Discutindo o alimento como fonte de suprimento das necessidades nutricionais do indivíduo, os alimentos têm o dever de estabelecer a manutenção, o reparo, o desenvolvimento e o crescimento, fornecendo todos os nutrientes em qualidade e quantidades apropriados e proporcionais, que vão ser utilizadas como fonte de energia e nutrimento para o organismo. Uma vez estabelecida a importância dos nutrientes nas diversas funções do organismo, é necessário determinar seus níveis de ingestão garantindo o balanceamento e a diversificação julgados adequados para atingir recomendações nutricionais de cada grupo etário (BISPO, 2006).

Cada alimento possui características próprias em relação ao aspecto, cor textura, aroma e sabor sendo constituído pelos nutrientes que apresentam funções energéticas (lipídeos, carboidratos e proteínas), plasmáticas ou construtoras (proteínas, água e minerais) e reguladoras das funções orgânicas (vitaminas e minerais) (ORNELLAS, 2008).

Mahan e Stump (2005) destacam que o ato de se alimentar é muito importante para sobrevivência humana, onde todos os alimentos possuem diversos nutrientes e cada um deles por sua vez tem uma função determinada no corpo humano. A função dos carboidratos, lipídeos e proteínas, por exemplo, é fornecer a energia necessária para a realização de todas as atividades cotidianas. Em contrapartida os chamados micronutrientes desempenham um papel primordial no organismo humano, servidos para a manutenção das atividades físiológicas. Com a diversidade de alimentos que podemos encontrar, é possível que sejam elaborados cardápios diversificados, e que estes sejam capazes de fornecer ao organismo todos os nutrientes essenciais a sua sobrevivência (MEZOMO, 2002).

\subsection{ALIMENTAÇÃO FORA DE CASA}

Observa-se, atualmente, índices crescentes no que se refere ao número de pessoas que tem se alimentado fora de suas residências. Diversos são os profissionais e as classes atendidas pelas empresas que servem refeições; dentre eles pode-se citar trabalhadores, estudantes, idosos, adolescentes, entre outros. Por essa razão, o mercado da alimentação coletiva está em grande ascensão (VAZ, 2003).

Nos dias atuais, este mercado em ascensão, já passou por mudanças significativas, no que diz respeito ao custo das refeições, as dificuldades na administração das unidades, e principalmente a preocupação com a qualidade higiênica sanitária do que é oferecido à clientela. Por essa razão, pode-se observar que em países como os Estados Unidos e a Europa 
Ocidental, novos processos tecnológicos de produção de alimentos para a coletividade, já estão sendo implantados, com o intuito de melhorar a qualidade dos alimentos e simultaneamente, aumentar a produtividade (PROENÇA, 1996).

Existem milhares de empresas de refeições coletivas no Brasil que serviram, no ano de 2007, cerca de 7,5 milhões de refeições/dia, com um faturamento de 8,4 bilhões de reais (ABERC, 2008). Estas empresas, assim como outros locais que processam alimentos para consumo fora do lar, têm a finalidade de oferecer alimentos com boas qualidades nutricionais, sensoriais e higiênico-sanitárias (ANTUNES et al., 2006).

De acordo com Associação Brasileira de Bares e Restaurantes - ABRASEL, daqui a 15 anos, o percentual de gastos com a alimentação fora de casa corresponderá a 40\% de toda a despesa com a comida da família. A esta expansão dos serviços de alimentação no que se refere ao tipo fast-food cresceu 15,5\% contra 9,7\% do varejo (ABRASEL, 2006). O termo fast food foi criação dos irmãos Richard e Maurice Mc Donald, no final da década de 40. Eles decidiram fazer da velocidade a essência do seu negócio e, para isso, acabaram com o atendimento personalizado, em que cada cliente poderia sugerir alteração no produto, segundo a sua escolha. Este sistema buscou solucionar o problema das grandes cidades no que se refere à alimentação no período de trabalho. Os produtos são fabricados segundo critérios de facilidade e rapidez na utilização. O segmento fast food tornou-se assim uma alternativa rápida de refeição, porém na maior parte das vezes carecendo de aporte nutritivo (BLEIL, 1998).

O uso de restaurantes fast food para refeições ou lanches é popular entre as pessoas que comem fora de casa. Os alimentos vendidos nestes restaurantes representam uma máquina de venda. Apesar de alguns restaurantes oferecerem uma seleção de alimentos saudáveis, a maioria dos itens alimentares fornece mais calorias provenientes da gordura (MAHAN; STUMP, 2005).

A ingestão de alimentos servidos em fast food cresceu consideravelmente nas últimas décadas, com isso o aumento no consumo de gordura e sódio, assim a ingestão frequente destes nutrientes em excesso está associado com diversos riscos à saúde, portanto torna-se importante avaliar os alimentos destes estabelecimentos, já que estes são consumidos diariamente (NERI; CURTI; FISBERG, 2006).

Atualmente, muitos alimentos fabricados nestes restaurantes são desenvolvidos a partir de matérias-primas disponíveis misturadas, associadas ao aspecto da atratividade, o que nem sempre garante a qualidade nutricional. Esses alimentos estão sempre disponíveis para o consumidor e são até mais atraentes, motivo pelo qual são escolhidos com mais frequência. $\mathrm{O}$ 
sucesso do fabricante de alimentos depende da sua habilidade em produzir alimentos mais atrativos que os alimentos comuns que a população costuma ingerir, e do marketing trabalhado no alimento, e por essa razão, serão comprados mesmo que não tenham nenhum benefício para oferecer e seu custo seja elevado (TURANO; ALMEIDA, 1999).

Os danos para a saúde que podem decorrer do consumo insuficiente de alimentos - ocasionando desnutrição - ou do consumo excessivo - ocasionando obesidade - são há muito conhecidos pelos seres humanos. Apenas mais recentemente, entretanto, acumulam-se evidências de que características qualitativas da dieta, principalmente a de restaurantes fast food, são igualmente importantes na definição do estado de saúde, em particular no que se refere a doenças crônicas da idade adulta (MONDINI; MONTEIRO, 1994).

Ocorre que, os restaurantes fast food buscam oferecer uma alimentação com sabores rebuscados como forma de atração e fidelização de sua clientela, sem a preocupação com o valor calórico e, conseqüentemente, nutricional da refeição. $\mathrm{O}$ excesso de ingredientes como sal, gordura e a inatividade física da população podem desencadear o sobrepeso e a obesidade, problemas cardiovasculares, além do aumento da pressão arterial (TOSCANO, 2004).

Destacamos que atualmente o perfil da clientela atendidas nos restaurantes, principalmente os de fast food, em geral são de trabalhadores que devido ao tempo não podem fazer suas refeições em casa (CARDOSO; SOUSA; SANTOS, 2005). Partindo deste ponto estes restaurantes passaram a introduzir nos seus cardápios outras opções de refeições para agradar e fidelizar a clientela, oferecendo pratos com alimentos que lembram as refeições preparadas em casa no horário do almoço, como: arroz, feijão, carnes, aves, peixes, saladas, purês, farofa, macarrão e sobremesas. Estas preparações não são tidas como preparações rápidas mais quando o cliente chega ao estabelecimento elas já estão prontas para serem servidas (PEGN, 2009). A cultura visual é muito valorizada para os restaurantes de fast food, come-se o alimento verdadeiro olhando para sua imagem fotográfica: maior, mais colorida e mais apetitosa do que o alimento real (RIAL, 1996).Vários fatores interferem na escolha dos alimentos no momento da refeição. Dentre eles o fator cultural, a variedade, a quantidade e a qualidade de ingredientes utilizados nos restaurantes (VEIROS; PROENÇA, 2003).

Devido a oferta destes alimentos no horário do almoço ser na grande maioria para trabalhadores esta pesquisa usou os parâmetros do Programa de Alimentação do Trabalhador para os cálculos e análises dos empratados. 


\subsection{OS PARÂMETROS NUTRICIONAIS DO PROGRAMA DE ALIMENTAÇÃO DO} TRABALHADOR.

O Programa de Alimentação do Trabalhador (PAT) é uma das mais antigas e importantes políticas de alimentação e nutrição do Brasil. Com inquestionável relevância social, é considerado um herdeiro de políticas públicas nacionais anteriores voltadas à alimentação do trabalhador. O PAT vem atraindo cada vez mais interesse para a promoção de estilos de vida saudáveis, pois, com o atual quadro epidemiológico, de avanço das doenças crônicas e da obesidade, o ambiente de trabalho vem sendo reconhecido como um local propício às modificações de comportamento precursor de doenças, não apenas associados à função ocupacional, mas também à dieta, à atividade física e ao tabagismo (BANDONI; JAIME, 2008).

O Programa de Alimentação do Trabalhador - PAT foi criado pela Lei N. 6321, de 14 de abril de 1976 e segundo seus mentores tem por objetivo melhorar as condições nutricionais dos trabalhadores, com repercussões positivas na qualidade de vida, na redução de acidentes de trabalho e no aumento da produtividade, assim como à prevenção de doenças profissionais. No PAT existem exigências nutricionais as serem atendidas. (SAVIO et al., 2005). O termo necessidade nutricional pode ser definido como as quantidades de nutrientes e de energia disponíveis nos alimentos que um indivíduo sadio deve ingerir para satisfazer suas necessidades fisiológicas e prevenir sintomas de deficiências (CUPPARI, 2002).

Os parâmetros nutricionais para a alimentação do trabalhador estabelecidos na Portaria Interministerial No 66, de 25 de agosto de 2006 deverão ser calculados com base nos seguintes valores diários de referência para macro e micronutrientes.

Tabela 1: Valores de referência dos nutrientes estabelecidos pelo PAT-2006.

\begin{tabular}{lc}
\hline \multicolumn{1}{c}{ NUTRIENTES } & VALORES DIÁRIOS \\
\hline Valor Energético Total (VET) & $2000 \mathrm{kcal}$ \\
\hline Carboidratos & $55-75 \%$ \\
\hline Proteínas & $10-15 \%$ \\
\hline Lipídeos & $15-30 \%$ \\
\hline Fibras & $>25 \mathrm{~g}$ \\
\hline Sódio $(\mathrm{Na})$ & $\leq 2400 \mathrm{mg}$ \\
\hline
\end{tabular}

FONTE: Programa de Alimentação do Trabalhador, 2006. 
De acordo com o PAT as refeições principais (almoço, jantar e ceia) deverão conter de seiscentas a oitocentas calorias, admitindo-se um acréscimo de vinte por cento (quatrocentas calorias) em relação ao Valor Energético Total -VET de duas mil calorias por dia e deverão corresponder a faixa de $30-40 \%$ (trinta a quarenta por cento) do VET diário (PAT, 2006). 


\section{METODOLOGIA}

O presente trabalho é um estudo do tipo transversal exploratório. Foi selecionada uma rede de restaurante fast food do Distrito Federal, configurando uma amostra de conveniência.

Diehi e Tatim (2004) expõem que as pesquisas exploratórias são indicadas para proporcionar maior familiaridade com o problema e assim torná-lo mais explícito para construir hipóteses o que envolve levantamento bibliográfico, além de realizar a pesquisa juntamente com pessoas que possuem experiência prática com o problema pesquisado. No fim da pesquisa analisada proporcionar maiores informações sobre o assunto e identificar formas de intervenção nas questões em estudo. A associação entre uma pesquisa exploratória e descritiva confirma-se pela utilização de técnicas padronizadas durante a coleta de dados e a observação sistemática durante o processo.

A referida rede escolhida tem 28 anos de funcionamento com mais de 250 lojas espalhadas pelo Brasil, tem seu horário de funcionamento variável dependendo de onde se encontra estabelecido, se for uma loja de shopping funciona de 11:00 às 22:00 horas, se for uma loja de rua funciona de 11:00 às 23:00, com cardápio variando desde pratos para crianças, pratos padrões, pratos grelhados, sanduíches, batata frita e sobremesas (sorvetes e petit gateau). O estabelecimento atende uma clientela variável, contudo sua clientela predominante no horário de almoço são os trabalhadores.

O restaurante possui 25 pratos no cardápio sendo que 10 destes pratos são considerados padrões básicos, compostos por dois acompanhamentos (arroz e feijão), duas guarnições (farofa e salada) e uma preparação protéica. Em virtude disto foram escolhidos para serem investigados no presente estudo. As preparações foram analisadas quanto à quantidade de macronutrientes como carboidratos, proteínas e lipídios, micronutriente sódio e a quantidade de fibras por causa das características da população. Os valores encontrados foram confrontados com os valores estabelecidos pelo PAT-2006.

Para base de cálculo foi usado o VET diário de duas mil calorias com percentual de 55 a $75 \%$ para o Carboidratos, 10 a 15\% para as proteínas e 15 a 30\% para as gorduras, o sódio $\leq 2400 \mathrm{mg} / \mathrm{d}$ e fibras $>25 \mathrm{~g} / \mathrm{d}(\mathrm{PAT}, 2006)$.

Os instrumentos usados foram elaboração de fichas técnicas de preparações (Akutsu et al., 2005), a Tabela Brasileira de Composição dos Alimentos (NEPA-UNICAMP, 2006), a Tabela para Avaliação de Consumo de Alimentos em Medidas Caseiras (PINHEIRO, 2004), para os alimentos não registrados nessas tabelas emprega-se os dados fornecidos pelos 
fabricantes contida nos rótulos dos alimentos e os Parâmetros Nutricionais do PAT (PAT, 2006). Após o cálculo de cada ficha técnica de preparação, avaliaram-se as quantidades e os percentuais de cada preparação presente no empratado. 


\section{RESULTADOS E DISCURSÃO}

No total, foram analisadas dez (10) preparações, é importante salientar que todos os empratados analisados apresentam os acompanhamentos fixos (arroz e feijão) e guarnições fixas (farofa e salada de alface e tomate com molho italiano). Existindo, no entanto uma mudança na preparação protéica que são: Peito de Frango Compactado, Hambúrgueres e Ovo, Bisteca de Porco, Bife de Maminha, Lingüiça Toscana, Peito de Frango Compactado e Empanado, Steak Bovino, Cupim, Costela Bovina e Filé Frango Sassami. Com dados colhidos dentro da instituição pesquisada obteve-se a informação de que estes pratos foram elaborados com um valor inferior aos demais pratos da rede devido em virtude de $79,5 \%$ da sua clientela $(\mathrm{n}=\mathrm{x})$ serem trabalhadores que no horário de almoço fazem a refeição 4,3 vezes em média por semana neste restaurante.

Os resultados estão descritos na Tabela 2 que mostra a composição nutricional e o valor de referência em percentual dos empratados oferecidos no restaurante fast food analisado na pesquisa.

Tabela 2 - Composição nutricional e o valor de referência dos empratados oferecidos no restaurante fast food do Distrito Federal.

\begin{tabular}{|c|c|c|c|c|c|c|c|c|c|c|}
\hline \multirow[b]{2}{*}{ Nutrientes } & \multicolumn{10}{|c|}{ Cardápio* } \\
\hline & PFC & HO & B & BM & $\mathbf{L T}$ & PFE & SB & CB & C & FFS \\
\hline VET (kcal) & 937 & 975 & 1006 & 887 & 1229 & 941 & 969 & 1078 & 1026 & 869 \\
\hline$\% \mathrm{VR}^{* *}$ & 46,8 & 48,7 & 50,3 & 44,3 & 61,4 & 47 & 48,5 & 53,9 & 51,3 & 43,4 \\
\hline Carboidratos (g) & 106,9 & 118,6 & 106,9 & 108,9 & 106,9 & 115,4 & 106,9 & 106,9 & 106,9 & 106,9 \\
\hline Carboidratos (\%) & 46 & 49 & 43 & 50 & 35 & 49 & 44 & 40 & 42 & 49 \\
\hline Proteínas (g) & 34,2 & 31,6 & 44,1 & 35,4 & 38,4 & 22,7 & 34,2 & 31,9 & 34,7 & 34,2 \\
\hline Proteínas (\%) & 15 & 13 & 17 & 16 & 13 & 10 & 14 & 12 & 14 & 16 \\
\hline Lipídeos (g) & 40,8 & 41,4 & 44,5 & 33,8 & 71,8 & 42,8 & 44,8 & 47,8 & 50,8 & 33,7 \\
\hline Lipídeos (\%) & 39 & 38 & 40 & 34 & 52 & 41 & 42 & 48 & 45 & 35 \\
\hline Sódio (mg) & 1917 & 2284 & 1709 & 1588 & 2745 & 1538 & 2205 & 1621 & 1598 & 1536 \\
\hline Fibras (g) & 13,7 & 15,5 & 12,6 & 12,6 & 12,6 & 12,6 & 12,6 & 12,6 & 12,6 & 12,6 \\
\hline
\end{tabular}

* Cardápio: PFC: peito de frango compactado; HO: hambúrgueres e ovo; B: bisteca; BM: bife de maminha; LT: linguiça toscana; PFE: peito de frango empanado; SB: steak bovino; CB: costela bovina; C: cupim; FFS: filé de frango sassami.

**\%VR: valores diários de referência com base em uma dieta de $2.000 \mathrm{kcal}$ ou $8400 \mathrm{kj}$.

Analisando os dados da tabela quanto à energia (VET), os valores encontrados, encontram-se dentro dos parâmetros estabelecido pelo PAT que é de 600 a 800 kcal admitindo-se um acréscimo de 400kcal. A exceção foi a linguiça toscana que excedeu, ficando com 1229kcal. O estudo de Sávio (2005) encontrou valores aquém da recomendação do PAT, já Dubiella e Martins (2006) constataram valores na maioria das refeições analisadas uma cota de energia superior à recomendada pelo PAT (2006). 
Todas as preparações apresentaram inadequação para o carboidrato. Os valores encontrados são menores que 50\% para o carboidrato, que deveriam estar dentro da faixa de 55 a $75 \%$, sendo portanto caracterizada como refeições hipoglicídicas. Fausto et al. (2001) já havia constatado que a contribuição percentual de carboidratos encontrada na sua pesquisa foi em média 45,6\%, valor este que esta abaixo da recomendação.

Os macronutrientes (carboidratos, lipídeos e proteínas) são de grande importância para a vida saudável do indivíduo. O carboidrato fornece primariamente combustível para o cérebro, medula, nervos periféricos e células vermelhas do sangue. Dessa forma, a ingestão alimentar insuficiente desse nutriente energético implica em danos ao sistema nervoso central, além da produção concomitante de corpos cetônicos, com graves prejuízos ao organismo, permitindo o catabolismo dos ácidos graxos em água e Acetil Coa. Já ingestão excessiva pode levar a obesidade e elevar os riscos cardíacos. (CORRÊA; SPERIDIÃO; NETO, 2006).

Quanto ao percentual de proteína dietética que deveria ser de 10 a 15\%, a maioria das preparações ficaram dentro da recomendação. Com exceção da Bisteca, Bife de Maminha e Filé de Frango Sassami que excederão um pouco a recomendação. Dentre os nutrientes a se considerar em uma alimentação balanceada, baseada em uma mistura de alimentos, destacamse as protéinas. Ela participa de processos vitais orgânicos, e constitui mais da metade do peso seco de muitos órgãos. No Brasil a principal fonte protéica da alimentação é derivada da ingestão de arroz e feijão. Esta mistura tem se mostrado adequada em teor nitrogenado, supre os aminoácidos essenciais e possui digestibilidade ao redor de $80 \%$ (MARCHINI et al., 1994).

Todas as preparações mostraram distribuição inadequada para o lipídeo. Esses resultados sugerem uma tendência pelos fast foods a preparações com alto teor de lipídeo. Todos os pratos apresentaram valores superiores ao recomendado que seria de 15 a $30 \%$, valores estes que variaram de 34 a $52 \%$. Caracterizando assim as preparações como hiperlipídicas.

O estudo de Moura (1986) observou que 15,78\% das empresas avaliadas em Pernambuco atendiam ao requisito energético protéico nas refeições principais. O consumo de lipídeos era elevado ao passo que o consumo de carboidrato era reduzido. Em uma dieta cerca de $95 \%$ da composição de gordura é representada por triacilgliceróis, sendo o restante constituído por outras formas de lipídeos, como fosfolipídios, ácidos graxos livres, colesterol e fitoesteróis (VAZ et al., 2006). A obesidade e o sobrepeso têm sido associados a um estilo de vida sedentário e a uma dieta rica em lipídios, sendo que esta parece permitir o excessivo 
consumo passivo de energia, devido a sua densidade energética e possivelmente sua baixa ação na saciedade (ROSADO; MONTEIRO, 2001).

Matos e Proença (2003) avaliaram a composição alimentar das refeições consumidas por operadores de uma Unidade de Alimentação e Nutrição. Este estudo também encontrou consumo glicídico inferior ás recomendações. A causa atribuída para esse fato, é que os mesmos funcionários mantêm uma dieta rica em lipídeos e proteínas, nutrientes que promovem a saciedade. Conseqüentemente, o consumo dos demais nutrientes será reduzido.

O sódio apresentou valores elevados para todas as preparações. $\mathrm{O}$ ideal de acordo com os parâmetros do PAT (2006) seria 960mg para o almoço, ou seja, 40\% do valor recomendado por dia. Sabe-se que em um restaurante o cliente tem a opção de acrescentar mais sal à refeição com isso agravando ainda mais a quantidade de sódio a refeição. Estes dados confirmam a necessidade em adoção de medidas preventivas quanto a ingestão diária de sódio, uma vez que as alterações iniciais da pressão arterial são freqüentemente associadas a presença de outros fatores de risco cardiovasculares (CERVATO et al., 1997).

O micronutriente sódio tem uma relação relevante na dieta do indivíduo, logo, um excesso deste ou uma falta acarreta danos irreversíveis ao organismo. O relatório do Institute of Medicine (IOM) mostra que, em todos os segmentos da população, há uma associação entre o aumento da ingestão de sódio e o aumento da pressão arterial, e que essa relação é a base para a recomendação rigorosa pelo IOM com relação à ingestão de sódio (IOM, 2001).

Baseado nas fichas técnicas de preparações e considerando que os acompanhamentos e as guarnições são fixas para todos os empratados, pode-se afirmar que os consumidores das refeições pesquisadas estão ingerindo sódio e lipídeo em excesso, o que pode causar hipertensão arterial ou mesmo agravar a doença nos que a possuem. Molhos, óleos em excesso, consumo de proteína animal com elevado teor lipídico e até o próprio sal de cozinha em excesso foram utilizados nas preparações estes mascaram o sabor natural dos alimentos. Por essa razão, pode-se sugerir a diminuição ou substituição de algumas proteínas por outras que tenham menor teor lipídico, acréscimo de condimentos naturais como salsinha, cebolinha, alho, coentro, orégano, erva doce e outros temperos além do óleo vegetal, de forma que realce o sabor das preparações sem que seja necessária a ingestão elevada de diversas fontes de sódio e de lipídeo.

As doenças cardiovasculares estão relacionadas com os hábitos alimentares de acordo com o estilo de vida, sendo assim dietas ricas em lipídeos, sódio e sedentarismo propiciam o aparecimento das mesmas. A ingestão destes alimentos, por um período prolongado de tempo, causam grandes danos ao coração e ao fígado (CERVATO et al., 1997). 
As doenças não transmissíveis representam, atualmente, importante problema de saúde pública nos países desenvolvidos. O Brasil, além de enfrentar o problema ainda não resolvido das doenças infecciosas e parasitárias, defronta-se com as doenças crônicas, de alto custo social e mais difícil prevenção. Entre os fatores de risco de maior probabilidade para o desenvolvimento das doenças cardiovasculares (DCV) destacam-se o fumo, a hipertensão arterial, as dislipidemias e o diabetes mellitus. A obesidade e a inatividade física foram positivamente associados com o risco de desenvolver DCV, constituindo-se nos fatores de risco mais significativos (MINISTÉRIO DA SAÚDE, 2009). Da mesma forma, o National Cholesterol Education Program e a Sociedade Brasileira de Cardiologia têm assinalado a fundamental implicação da obesidade, da dieta e da inatividade física no risco cardiovascular.

Já as fibras contribuíram para os valores dentro da recomendação de $40 \%$ ou mais. Este resultado deve-se a contribuição do feijão e da salada nos pratos, conclui-se que a presença deste nutriente é suficiente no cardápio do almoço, levando-se em consideração que o indivíduo venha a consumir os restantes de fibra alimentar nas outras refeições do dia para completar a recomendação diária.

A fibra alimentar é classificada como uma classe de compostos de origem vegetal, que possuem na sua composição polissacarídeos e substâncias associadas que quando ingeridos não sofrem hidrólise, digestão e absorção no intestino delgado de humanos (CUPPARI, 2002). Os hábitos alimentares exercem grande influência sobre o crescimento, desenvolvimento e saúde geral dos indivíduos. Estudos recentes têm mostrado que dietas ricas em fibras protegem contra obesidade, doenças cardiovasculares, diabetes e alguns tipos de câncer (NEUTZLING et al., 2007).

Os resultados encontrados mostram a importância da avaliação nutricional dos empratados. Por serem refeições onde se encontram carne, arroz, feijão e salada o consumidor tem em mente que está comendo uma refeição saudável em qualidade e quantidades suficientes. Esses achados são preocupantes se consumidos diariamente por um período de tempo prolongado, o problema, entretanto, é que os alimentos analisados possuem elevados índices de gorduras e sódio o que não está de acordo com as recomendações de uma dieta saudável e balanceada. Por todos os motivos apresentados, sugere-se a elaboração e implantação das fichas técnicas de preparação e a busca por receitas tradicionais, onde não há adição de ingredientes que tornam a preparação nutricionalmente inadequada. 


\section{CONCLUSÃO}

Com base nos achados da pesquisa conclui-se que as refeições analisadas e vendidas nesta rede de restaurantes fast food apresentaram alto percentual de lipídeos e sódio, podendo levar os trabalhadores que se alimentam diariamente destas refeições e que não praticam atividade física a um ganho de peso excessivo e possíveis problemas cardiovasculares. A alimentação nutricionalmente adequada pode atuar tanto na prevenção como no tratamento destas doenças. Ressalta-se que todos os nutrientes devem estar presentes nas refeições em quantidade e percentuais recomendados.

Assim, tem-se verificado cada vez mais a importância da avaliação dos hábitos alimentares da população. Pela análise dietética, as necessidades nutricionais das pessoas podem ser identificadas e programas de educação nutricional podem ser implementados, a fim de se proporcionar melhores condições de saúde para a população.

Finalmente, são necessários estudos posteriores nos quais os objetivos sejam avaliar hábitos alimentares e prática de atividades físicas por parte destes trabalhadores. 


\section{REFERÊNCIAS BIBLIOGRÁFICAS}

AKUTSU, RITA DE CÁSSIA; BOTELHO, RAQUEL ASSUNÇÃO; CAMARGO, ERIKA BARBOSA; SÁVIO, KARIN ELEONORA OLIVEIRA; ARAÚJO, WILMA COELHO. A ficha técnica de preparação como instrumento de qualidade na produção de refeições. Revista de Nutrição. Vol.18, nº 2. Campinas. 2005.

AKUTSU, RITA DE CÁSSIA; BOTELHO, RAQUEL ASSUNÇÃO; CAMARGO, ERIKA BARBOSA; SÁVIO, KARIN ELEONORA OLIVEIRA; ARAÚJO, WILMA COELHO. Adequação das boas práticas de fabricação em serviços de alimentação. Revista de Nutrição. Vol. 18, n³. Campinas. 2005.

ANTUNES, MARIA APARECIDA; ANDRADE NÉLIO JOSÉ; SILVA, ARTUR CARLOS BARBOSA; AZEREDO, RAQUEL MONTEIRO CORDEIRO; LOPES, FRANCILINE APARECIDA. Sistema multimídia de apoio à decisão em procedimentos de higiene para unidades de alimentação e nutrição. Revista de Nutrição. Vol.19, nº1. Campinas. 2006.

Associação Brasileira das Empresas de Refeições coletivas - ABERC (INTERNET). Mercado real. Disponível em: http://www.aberc.com.br/mercadoreal. Acesso em $11 / 10 / 2008$.

Associação Brasileira de Bares e Restaurantes - ABRASEL (INTERNET). Disponível em www.abrasel.com.br. Acesso em 11/10/08.

BANDONI, DANIEL H; JAIME PATRÍCIA C. A qualidade das refeições de empresas cadastradas no Programa de Alimentação do Trabalhador na cidade de São Paulo. Revista de Nutrição, vol.21, n²2. Campinas. 2008.

BISPO, JANAINA SARMENTO. Perfil alimentar referente ao desjejum de professores da Universidade de Brasilia - UNB. Dissertação (mestrado) Departamento de Nutrição, Faculdade Ciências da Saúde, Universidade de Brasília, Brasília, 2006.

BLEIL, SUSANA INEZ. O Padrão Alimentar Ocidental: Considerações sobre a mudança de hábitos no Brasil. Revista Cadernos de Debate. Vol. VI, UNICAMP, 1998.

CANESQUI, ANA MARIA. A qualidade dos alimentos: análise de algumas categorias da dietética popular. Revista de Nutrição. Vol. 20, n² Campinas. 2007.

CARDOSO, RYZIA DE CÁSSIA VIEIRA; SOUZA, EVA VILMA ARAÚJO; SANTOS, PÁTRÍCIA QUADROS DOS SANTOS. Unidades de alimentação e Nutrição nos campi da Universidade Federal da Bahia: um estudo sob a perspectiva do alimento seguro. Revista de Nutrição. Vol.18, nº 5. Campinas. 2005.

CERVATO, ANA MARIA; MAZZILLI, ROSA NILDA; MARTINS, INÊS SALAS; MARUCCI, MARIA FÁTIMA NUNES. Dieta habitual e fatores de risco para doenças cardiovasculares. Revista de Saúde Pública. São Paulo, vol.31, nº 3, junho. 1997. 
CHAMPE, PAMELA C.; FERRIER, DENISE R.; HARVEY, RICHARD A. Bioquímica Ilustrada. São Paulo. Editora ARTMED - BOOKMAN, 2005.

COELHO, NELLY NOVAES. A emancipação da mulher e a imprensa feminina (2001). Documento eletrônico disponível em http://kplus.cosmo.com.br/materia.asp?co=119\&rv=Literatura. Acesso 21 janeiro de 2009.

CORRÊA, FERNANDA F.; SPERIDIÃO, PATRÍCIA G.; NETO, ULYSSES F. Estrutura e Função dos Carboidratos. The Eletronic Journal of Pediatric Gastroenterology, Nutrition and Liver Diaseases. Vol. 10, $\mathrm{n}^{\mathrm{o}}$ 2, Junho. 2006.

CUPPARI, LILIAN. Guia de Nutrição: Nutrição Clínica no Adulto. São Paulo. Manole, 2002.

DAMASCENO, K.S.F.S.C.; ALVES, M.A.; FREIRE, I.M.G.; TÔRRES, G.F.; AMBRÓSIO, CLB.; GUERRA, NB. Condições higiênico-sanitárias de "self-services" do entorno da UFPE e das saladas cruas por elas servidas. Higiene Alimentar. 2002.

DEPS, VERA LÚCIA. Atividade e Bem-estar Psicológico na Maturidade. In: NERI, A. L. (Org.). Qualidade de vida e idade madura. 5. ed. São Paulo: Papirus, 1993.

DIEHL, ASTOR ANTÔNIO; TATIM, DENISE CARVALHO. Pesquisa em ciências sociais aplicadas: métodos e técnicas. São Paulo: Prentice Hall, 2004.

DUBIELLA, JAQUELINE; MARTINS, ADRIANA. Comparação da Composição Nutricional de Cardápios Oferecidos a Trabalhadores de um Município do Oeste do Paraná com as Novas Recomendações do Programa de Alimentação ao Trabalhador - PAT. Faculdade Assis Gurgacz - FAG. PARANÁ, 2006.

FAUSTO, MARIA ARLENE; ANSALONI, JOSÉ ARMANDO; SILVA, MARCELO EUSTÁQUIO; JÚNIOR, JAIR GARCIA; DEHR, AKEBER ABOU; CÉSAR, THAÍS BORGES. Determinação do Perfil dos Usuários e da Composição Química e Nutricional da Alimentação Oferecida no Restaurante Universitário da Universidade Estadual Paulista, Araraquara, Brasil. Revista de Nutrição. Vol. 14, n³. Campinas. 2001

INSTITUTE OF MEDICINE/ FOOD AND NUTRITION BOARD. Dietary Reference Intakes for vitamin $\mathrm{A}$, vitamin $\mathrm{K}$, arsenic, boron, chromium, copper, iodine, iron, manganese, molibidenum, nickel, silicon, vnadium and zinco. Washington, National Academy Press, 2001.

KAC, GILBERTO; SICHIERI, ROSELY; GIGANTE, DENISE PETRUCCI (org). Epidemiologia Nutricional. Rio de Janeiro. Ed. Fiocruz/Atheneu. 2007.

MAHAN, L. KATHLEEN; STUMP, SYLVIA ESCOTT. Krause - Alimentos, Nutrição e dietoterapia. [tradução Andréa Favano et al.]. 11 a ed. São Paulo. ROCA, 2005. 
MARCHINI, J. SERGIO; RODRIGUES, MARGARETH M. P.; CUNHA, SELMA F. C.; FAUSTO, M. A.; VANNUCCH, HELIO; OLIVEIRA, J. E. DUTRA. Cálculo das recomendações de ingestão protéica: aplicação a pré-escolar, escolar e adulto utilizando alimentos brasileiros. Revista Saúde Pública. Vol. 28, nº2. São Paulo. 1994.

MATOS, CRISTINA HENSCHEL; PROENÇA, ROSSANA PACHECO DA COSTA. Condições de Trabalho e Estado Nutricional de Operadores do Setor de Alimentação Coletiva: Um Estudo de Caso. Revista de Nutrição. Campinas, vol. 04, 2003.

MENASCHE, RENATA; MARQUES, FLÁVIA CHARÃO; ZANETTI, CÂNDIDA. Autoconsumo e segurança alimentar: a agricultura familiar a partir dos saberes e práticas da alimentação. Revista de Nutrição. Vol.21. Campinas. 2008.

MEZOMO, IRACEMA F. DE BARROS. Os Serviços de Alimentação: Planejamento e Administração. $5^{\text {a }}$ ed. São Paulo: Manole, 2008.

MINISTÉRIO DA SAÚDE. Brasil. Informações em Saúde — Mortalidade. [online] [citado 2009 fev. 16] Disponível em: http://www.saude.gov.br/inform/indica/indica

MONDINI, LENICE; MONTEIRO, CARLOS A. Mudanças no padrão de alimentação da população urbana brasileira (1962-1988). Revista Saúde Pública. Vol. 24, 1994. São Paulo.

MOURA, JOSENILDA BARRETO. Avaliação do Programa de Alimentação do Trabalhador, no Estado de Pernambuco, Brasil. Revista Saúde Pública. São Paulo, vol. 02, 1986.

Tabela brasileira de composição de alimentos / NEPA-UNICAMP. Versão II. 2a edição Campinas, SP: NEPA-UNICAMP, 2006.

NERI, LENYCIA DE CASSIA LOPES; CURTI, LADEIA RODRIGUES.; FISBERG, REGINA MARA. Avaliação do Consumo Alimentar de Trabalhadores de Rede Fast Food. Revista de nutrição em Pauta. São Paulo, edição jul/ago, 2006.

NEUTZLING, MARILDA BORGES; ARAÚJO, C. L. PAVIN; VIEIRA, MARIA DE FÁTIMA ALVES; HALLAL, PEDRO CURI; MENEZES, ANA MARIA BAPTISTA. Frequência de consumo de dietas ricas em gordura e pobres em fibra entre adolescentes. Revista Saúde Pública. Vol. 41, n³. São Paulo. 2007.

ORNELAS, LIESELOTTE HOESCHL; SHIZUKO, KAJISHIMA; VERRUMA-BERNADI, MARIA REGINA. Técnica e Dietética: Seleção e Preparo de Alimentos. 8 a edição. Atheneu. 2008.

Pequenas Empresas e Grandes Negócios - PEGN. Fast food saudável é boa opção de negócio. Disponível: http://pegntv.globo.com/Pegn. Acesso 17/05/09.

PINHEIRO, ANA BEATRIZ VIEIRA. Tabela para avaliação de consumo de alimentos em medidas caseiras. São Paulo. $5^{\text {a }}$ edição. Atheneu. 2004. 
PROENÇA, ROSANA PACHECO DA COSTA. Novas tecnologias para a produção de refeições coletivas: recomendações de introdução para a realidade brasileira. Revista Nutrição. Campinas. 1996.

Programa de Alimentação do Trabalhador -PAT. (INTERNET). Disponível http://www.mte.gov.br/pat. Acesso em 11/11/08.

RIAL, CARMEM SILVIA. A questão alimentar: Fast Food. Nutrição em Pauta. São Paulo. 2004.

ROSADO, ELIANE LOPES.; MONTEIRO, JOSEFINA BRESSAN RESENDE. Obesidade e a substituição de macronutrientes da dieta. Revista de Nutrição. Campinas. 2001.

SAVIO, KARIN ELEONORA OLIVEIRA; COSTA, TERESA HELENA MACEDO; MIAZAKI, ÉDINA; SCHMITZ, BETHSÁIDA DE ABREU SOARES. Avaliação do almoço servido a participantes do programa de alimentação do trabalhador. Revista Saúde Pública. Vol.39, n², São Paulo, 2005.

SHILS MAURICE E.; OLSON JAMES A.; SHIKE MOSHE.; ROSS A. CATHARINE. Tratado de Nutrição Moderna na Saúde e na Doença. São Paulo. Manole, 2003.

TORAL NATACHA; SLATER BETZABETH; CINTRA ISA DE PÁDUA; FISBERG MAURO. Comportamento alimentar de adolescentes em relação ao consumo de frutas e verduras. Revista de Nutrição. Vol.19. Campinas. 2006.

TOSCANO, CRISTINA MARIA. As campanhas nacionais para detecção das doenças crônicas não-transmissíveis: diabetes e hipertensão arterial. Revista Ciência e Saúde Coletiva, 9(4): 885-895, 2004.

TURANO, WILMA; ALMEIDA, C. C. C. Educação Nutricional. In: GOUVEIA, E.L.C. (Org.). Nutrição Saúde \& Comunidade. $2^{\circ}$ edição, Rio de Janeiro: Revinter, 1999. Cap. 3, p. 57-77.

VAZ, CÉLIA SILVÉRIO. Alimentação de coletividade: uma abordagem gerencial. Manual prático do gestor de serviços. 2 ed. Brasília, 2003.

VAZ, JULIANA DOS SANTOS; DEBONI, FABÍOLA; AZEVEDO, MIRELA JOBIM; GROSS, JORGE LUIZ; ZELMANOVITZ, THEMIS. Ácidos graxos como marcadores biológicos da ingestão de gorduras. Revista de Nutrição. Vol.19, nº 4. Campinas. 2006.

VEIROS, MARCELA BORO; PROENÇA, ROSSANA PACHECO DA COSTA. Avaliação Qualitativa das Preparações do Cardápio em uma Unidade de Alimentação e Nutrição Método AQPC. Revista Nutrição em Pauta. São Paulo, Ano XI, nº. 62, 2003. 


\section{APÊNDICE}

\section{FICHAS TÉCNICAS}

NOME DA PREPARAÇ̃̃O: ARROZ BRANCO

\begin{tabular}{|c|c|c|c|c|c|}
\hline INGREDIENTES & $\begin{array}{l}\text { Peso } \\
\text { Bruto }\end{array}$ & $\begin{array}{c}\text { Peso } \\
\text { líquido }\end{array}$ & $\begin{array}{c}\text { Per } \\
\text { capita }\end{array}$ & & Modo de Preparo \\
\hline Arroz & $2,5 \mathrm{~kg}$ & $2,5 \mathrm{~kg}$ & $71,4 \mathrm{~g}$ & \multirow{7}{*}{. 2.} & \multirow{7}{*}{$\begin{array}{l}\text { Lavar o arroz na bacia até } \\
\text { cobri-lo com água por duas a } \\
\text { três vezes e depois usar o } \\
\text { escorredor para seca-lo. } \\
\text { Em uma panela, colocar a } \\
\text { cebola, o óleo e a margarina. } \\
\text { Deixar a cebola amolecer e } \\
\text { colocar a água e o sal. Tampar } \\
\text { a panela e deixar ferver a água. } \\
\text { Colocar o arroz, mexer bem e } \\
\text { tampar. Após ferver novamente } \\
\text { deixar o fogo baixo. } \\
\text { quando secar a água, abaixar o } \\
\text { fogo ao mínimo. Esperar secar } \\
\text { cerca de 4minutos e desligar o } \\
\text { fogo. Retirar a panela do fogo } \\
\text { e deixar tampada para um } \\
\text { perfeito cozimento }( \pm \quad 15 \\
\text { minutos). }\end{array}$} \\
\hline Água & 31 & 31 & - & & \\
\hline Sal & $60 \mathrm{~g}$ & $60 \mathrm{~g}$ & $1,7 \mathrm{~g}$ & & \\
\hline Margarina & $60 \mathrm{~g}$ & $60 \mathrm{~g}$ & $1,7 \mathrm{~g}$ & & \\
\hline Óleo & $250 \mathrm{ml}$ & $250 \mathrm{ml}$ & $7,1 \mathrm{ml}$ & & \\
\hline cebola & $80 \mathrm{~g}$ & $80 \mathrm{~g}$ & $2,2 \mathrm{~g}$ & & \\
\hline \multicolumn{4}{|c|}{ FATOR DE COCÇÃO = 2,5 } & & \\
\hline
\end{tabular}

VET (per capita) $322 \mathrm{kcal}$

$\begin{array}{lll}\text { CHO } & 56,4 \mathrm{~g} & 225,6 \mathrm{kcal} \\ \text { PTN } & 5,1 \mathrm{~g} & 20,4 \mathrm{kcal} \\ \text { LIP } & 8,4 \mathrm{~g} & 75,6 \mathrm{kcal} \\ \text { SOD } & 390 \mathrm{mg} & - \\ \text { FIBRAS } & 1,14 \mathrm{~g} & -\end{array}$


NOME DA PREPARAĈ̃O: FEIJÃO PRETO

\begin{tabular}{|c|c|c|c|c|}
\hline INGREDIENTES & $\begin{array}{c}\text { Peso } \\
\text { Bruto }\end{array}$ & $\begin{array}{c}\text { Peso } \\
\text { líquido }\end{array}$ & $\begin{array}{c}\text { Per } \\
\text { capita }\end{array}$ & Modo de Preparo \\
\hline Feijão Preto & $1 \mathrm{~kg}$ & $1 \mathrm{~kg}$ & $38 \mathrm{~g}$ & \multirow{6}{*}{$\begin{array}{l}\text { 1. Escolher bem o feijão e } \\
\text { deixar de remolho por } \\
\text { aproximadamente } 2 \text { horas. } \\
\text { Desprezar a água do } \\
\text { remolho. } \\
\text { 2. Colocar na panela de } \\
\text { pressão a água do } \\
\text { cozimento com sal, pois o } \\
\text { mesmo evita que a casca } \\
\text { solte. Reservar } 1 / 3 \text { do caldo } \\
\text { do cozimento. } \\
\text { 3. Na frigideira colocar o óleo } \\
\text { de bacon e o alho bem } \\
\text { picado. Deixar o alho } \\
\text { dourar bem e adicionar } 1 / 3 \\
\text { do feijão bem amassado. } \\
\text { 4. Voltar o feijão para a } \\
\text { panela, misturar bem e } \\
\text { deixar ferver até engrossar. } \\
\text { Para afina-lo utilizar o } \\
\text { caldo reservado e não água. }\end{array}$} \\
\hline Óleo de bacon & $150 \mathrm{ml}$ & $150 \mathrm{ml}$ & $5,7 \mathrm{ml}$ & \\
\hline sal & $50 \mathrm{~g}$ & $50 \mathrm{~g}$ & $1,9 \mathrm{~g}$ & \\
\hline alho & $30 \mathrm{~g}$ & $30 \mathrm{~g}$ & $0,27 \mathrm{~g}$ & \\
\hline água & 3,51 & 3,51 & - & \\
\hline \multicolumn{4}{|c|}{$\begin{array}{l}\text { FATOR DE COCÇÃO }=3,0 \\
\text { RENDIMENTO }=26 \text { porções }\end{array}$} & \\
\hline
\end{tabular}

\begin{tabular}{lll}
\multicolumn{2}{l}{ VET (per capita) } & $176 \mathrm{kcal}$ \\
CHO & $22,57 \mathrm{~g}$ & $90,28 \mathrm{kcal}$ \\
PTN & $8,3 \mathrm{~g}$ & $33,2 \mathrm{kcal}$ \\
LIP & $6,26 \mathrm{~g}$ & $56,3 \mathrm{kcal}$ \\
SOD & $417 \mathrm{mg}$ & - \\
FIBRAS & $8,32 \mathrm{~g}$ & -
\end{tabular}


NOME DA PREPARAÇ̃̃O: FAROFA

\begin{tabular}{|c|c|c|c|c|}
\hline INGREDIENTES & $\begin{array}{c}\text { Peso } \\
\text { Bruto }\end{array}$ & $\begin{array}{c}\text { Peso } \\
\text { líquido }\end{array}$ & $\begin{array}{c}\text { Per } \\
\text { capita }\end{array}$ & Modo de Preparo \\
\hline Farinha & $2,5 \mathrm{~kg}$ & $2,5 \mathrm{~kg}$ & $26 \mathrm{~g}$ & 1. Higienizar bem a cebola, \\
\hline Sal & $50 \mathrm{~g}$ & $50 \mathrm{~g}$ & $0,5 \mathrm{~g}$ & $\begin{array}{l}\text { picar o bacon em } 0,5 \mathrm{~cm} \text { e a } \\
\text { cebola de } 1 \mathrm{~cm}\end{array}$ \\
\hline Ovos & $300 \mathrm{~g}$ & $300 \mathrm{~g}$ & $3,1 \mathrm{~g}$ & 2. Colocar na panela: o bacon, \\
\hline Bacon & $400 \mathrm{~g}$ & $400 \mathrm{~g}$ & $4,2 \mathrm{~g}$ & $\begin{array}{l}\text { a cebola, a margarina, o } \\
\text { óleo e o sal. Lavar ao fogo }\end{array}$ \\
\hline Margarina & $400 \mathrm{~g}$ & $400 \mathrm{~g}$ & $4,2 \mathrm{~g}$ & até o bacon dourar e a \\
\hline Óleo de bacon & $250 \mathrm{ml}$ & $250 \mathrm{ml}$ & $2,6 \mathrm{ml}$ & $\begin{array}{l}\text { cebola amolecer. } \\
\text { 3. Retirar do fogo e reservar. }\end{array}$ \\
\hline Cebola & $400 \mathrm{~g}$ & $400 \mathrm{~g}$ & $4,2 \mathrm{~g}$ & 4. Colocar os ovos em uma \\
\hline \multicolumn{4}{|c|}{$\begin{array}{l}\text { RENDIMENTO = } 95 \text { porções } \\
\text { PORÇÃO }=45 \text { gramas }\end{array}$} & $\begin{array}{l}\text { óleo suficiente para não } \\
\text { grudar na panela. Levar ao } \\
\text { fogo, mexer com } \\
\text { movimentos circulares para } \\
\text { os grumos ficarem } \\
\text { pequenos. Fazer um } \\
\text { mexido e retirar do fogo e } \\
\text { reservar. } \\
\text { 5espejar a mistura líquida } \\
\text { por cima da farinha e por } \\
\text { último os ovos e mexa } \\
\text { bem. }\end{array}$ \\
\hline
\end{tabular}

$\begin{array}{lll}\text { VET (per capita) } & 181,8 \mathrm{kcal} \\ \text { CHO } & 24,5 \mathrm{~g} & 98 \mathrm{kcal} \\ \text { PTN } & 1,37 \mathrm{~g} & 5,48 \mathrm{kcal} \\ \text { LIP } & 8,68 \mathrm{~g} & 78,16 \mathrm{kcal} \\ \text { SOD } & 159,5 \mathrm{mg} & - \\ \text { FIBRAS } & 1,84 \mathrm{~g} & -\end{array}$


NOME DA PREPARACÃO: SALADA CRUA COM MOLHO ITALIANO

\begin{tabular}{|c|c|c|c|c|}
\hline INGREDIENTES & $\begin{array}{c}\text { Peso } \\
\text { Bruto }\end{array}$ & $\begin{array}{c}\text { Peso } \\
\text { líquido }\end{array}$ & $\begin{array}{c}\text { Per } \\
\text { capita }\end{array}$ & Modo de Preparo \\
\hline Alface & $1,5 \mathrm{~kg}$ & $1,5 \mathrm{~kg}$ & $25 \mathrm{~g}$ & \multirow{4}{*}{$\begin{array}{l}\text { 1. Higienizar bem o tomate e } \\
\text { colocar de molho em uma } \\
\text { vasilha de plástico com } \\
\text { solução sanitizante de } \\
\text { acordo com o tempo do } \\
\text { fabricante. } \\
\text { 2. Corta o tomate em pedaço } \\
\text { bem pequenos. } \\
\text { 3. Colocar o alface ja } \\
\text { higienizado do fabricante } \\
\text { em uma cuba. } \\
\text { 4. Colocar o tomate cortade } \\
\text { em outra cuba. } \\
\text { 5. Porcionar somente na hor } \\
\text { de servir e adicionar } \\
\text { molho após a montagem de } \\
\text { salada }\end{array}$} \\
\hline Tomate & $1,5 \mathrm{~kg}$ & $1,5 \mathrm{~kg}$ & $25 \mathrm{~g}$ & \\
\hline Molho italiano & $375 \mathrm{ml}$ & $357 \mathrm{ml}$ & $12,5 \mathrm{ml}$ & \\
\hline \multicolumn{4}{|c|}{$\begin{array}{l}\text { RENDIMENTO = } 60 \text { porções } \\
\text { PORÇÃO }=50 \text { gramas }\end{array}$} & \\
\hline
\end{tabular}

VET (per capita) $\quad 49,2 \mathrm{kcal}$

$\mathrm{CHO} \quad 3,46 \mathrm{~g} \quad 13,8 \mathrm{kcal}$

PTN $\quad 0,42 \mathrm{~g} \quad 1,68 \mathrm{kcal}$

LIP $\quad 3,57 \mathrm{~g} \quad 32,1 \mathrm{kcal}$

SOD $\quad 185,3 \mathrm{mg} \quad-$

FIBRAS $1,32 \mathrm{~g} \quad-$ 
NOME DA PREPARAÇ̃̃O: ÓLEO DE BACON

\begin{tabular}{|l|c|c|l|}
\hline \multicolumn{1}{|c|}{ INGREDIENTES } & $\begin{array}{c}\text { Peso } \\
\text { Bruto }\end{array}$ & $\begin{array}{c}\text { Peso } \\
\text { líquido }\end{array}$ & Modo de Preparo \\
\hline Bacon & $200 \mathrm{~g}$ & $200 \mathrm{~g}$ & $\begin{array}{l}\text { 1. bata tudo no liquidificar e } \\
\text { conserve na geladeira por no } \\
\text { máximo 12 horas. }\end{array}$ \\
\hline Óleo de soja & $900 \mathrm{ml}$ & $900 \mathrm{ml}$ & \\
\cline { 1 - 2 } & & \\
\hline
\end{tabular}

$\begin{array}{lll}\text { VET (per capita) } & 930 \mathrm{kcal} \\ \text { CHO } & - & - \\ \text { PTN } & 2,3 \mathrm{~g} & 9,2 \mathrm{kcal} \\ \text { LIP } & 102 \mathrm{~g} & 918 \mathrm{kcal} \\ \text { SOD } & 10 \mathrm{mg} & - \\ \text { FIBRAS } & - & -\end{array}$


NOME DA PREPARAĈ̃O: PEITO DE FRANGO COMPACTADO

\begin{tabular}{|c|c|c|c|}
\hline INGREDIENTES & $\begin{array}{c}\text { Peso } \\
\text { Bruto }\end{array}$ & $\begin{array}{c}\text { Peso } \\
\text { líquido }\end{array}$ & Modo de Preparo \\
\hline Peito de frango compactado & $60 \mathrm{~g}$ & $60 \mathrm{~g}$ & $\begin{array}{l}\text { 1. Colocar o peito de frango } \\
\text { compactado na Chair Broiler } \\
\text { (Grill) por aproximadamente 5 } \\
\text { a } 7 \text { minutos. Quando estiver } \\
\text { levemente dourada colocar no } \\
\text { prato já montado. }\end{array}$ \\
\hline PORÇÃO =120 gramas (2unidades) & \\
\hline
\end{tabular}

\begin{tabular}{lll}
\multicolumn{2}{l}{ VET (per capita) } & $208 \mathrm{kcal}$ \\
CHO & $1,1 \mathrm{~g}$ & $4,4 \mathrm{kcal}$ \\
PTN & $19 \mathrm{~g}$ & $76 \mathrm{kcal}$ \\
LIP & $14 \mathrm{~g}$ & $126 \mathrm{kcal}$ \\
SOD & $765 \mathrm{mg}$ & - \\
FIBRAS & $1,1 \mathrm{~g}$ & -
\end{tabular}


NOME DA PREPARACÃO: HAMBÚRGUERES E OVO

\begin{tabular}{|c|c|c|c|}
\hline INGREDIENTES & $\begin{array}{l}\text { Peso } \\
\text { Bruto }\end{array}$ & $\begin{array}{c}\text { Peso } \\
\text { líquido }\end{array}$ & Modo de Preparo \\
\hline Hambúrguer & $50 \mathrm{~g}$ & $50 \mathrm{~g}$ & \multirow{5}{*}{$\begin{array}{l}\text { 1. Colocar dois hambúrgueres } \\
\text { na chapa por } \\
\text { aproximadamente } \\
\text { minutos e deixar dourar dos } \\
\text { dois lados. } \\
\text { 2. Colocar o ovo com o óleo } \\
\text { dentro do suporte em cima } \\
\text { da chapa, colocar o sal e } \\
\text { deixar por } 4 \text { minutos. } \\
\text { 3. Levar os hambúrgueres e o } \\
\text { ovo para o prato já } \\
\text { montado. }\end{array}$} \\
\hline Ovo & $25 \mathrm{~g}$ & $25 \mathrm{~g}$ & \\
\hline Óleo & $5 \mathrm{ml}$ & $5 \mathrm{ml}$ & \\
\hline Sal & $0,5 \mathrm{~g}$ & $0,5 \mathrm{~g}$ & \\
\hline \multicolumn{3}{|c|}{$\begin{array}{l}\text { PORÇÃO = } 100 \text { gramas ( } 2 \text { unidades de hambúrgueres) e } 25 \mathrm{~g} \text { de } \\
\text { Ovo. }\end{array}$} & \\
\hline
\end{tabular}

\begin{tabular}{lll}
\multicolumn{2}{l}{ VET (per capita) } & $246 \mathrm{kcal}$ \\
CHO & $11,7 \mathrm{~g}$ & $48,4 \mathrm{kcal}$ \\
PTN & $16,45 \mathrm{~g}$ & $65,8 \mathrm{kcal}$ \\
LIP & $14,6 \mathrm{~g}$ & $131,4 \mathrm{kcal}$ \\
SOD & $1132 \mathrm{mg}$ & - \\
FIBRAS & $2,9 \mathrm{~g}$ & -
\end{tabular}


NOME DA PREPARAÇ̃̃O: BISTECA

\begin{tabular}{|c|c|c|c|}
\hline INGREDIENTES & $\begin{array}{c}\text { Peso } \\
\text { Bruto }\end{array}$ & $\begin{array}{c}\text { Peso } \\
\text { líquido }\end{array}$ & Modo de Preparo \\
\hline Bisteca suína & $150 \mathrm{~g}$ & $120 \mathrm{~g}$ & 1. Colocar sal e pimenta sobre \\
\hline Sal & $1 \mathrm{~g}$ & $1 \mathrm{~g}$ & $\begin{array}{l}\text { a bisteca. } \\
\text { 2. Coloca-la na Chair Broiler }\end{array}$ \\
\hline Pimenta do reino & $0,5 \mathrm{~g}$ & $0,5 \mathrm{~g}$ & (Grill) por \\
\hline \multicolumn{3}{|c|}{ PORÇÃO = 120 gramas } & $\begin{array}{l}\text { minutos. } \\
\text { 3. Levar a Bisteca para o } \\
\text { prato já montado. }\end{array}$ \\
\hline
\end{tabular}

\begin{tabular}{lll}
\multicolumn{2}{l}{ VET (per capita) } & $292 \mathrm{kcal}$ \\
CHO & - & - \\
PTN & $28,9 \mathrm{~g}$ & $115,6 \mathrm{kcal}$ \\
LIP & $17,7 \mathrm{~g}$ & $159,3 \mathrm{kcal}$ \\
SOD & $550 \mathrm{mg}$ & - \\
FIBRAS & - & -
\end{tabular}


NOME DA PREPARAÇÃO: BIFE DE MAMINHA

\begin{tabular}{|c|c|c|c|}
\hline INGREDIENTES & $\begin{array}{c}\text { Peso } \\
\text { Bruto }\end{array}$ & $\begin{array}{c}\text { Peso } \\
\text { líquido }\end{array}$ & Modo de Preparo \\
\hline Bife de Maminha & $120 \mathrm{~g}$ & $120 \mathrm{~g}$ & 1. Colocar sal e pimenta sobre \\
\hline Sal & $1 \mathrm{~g}$ & $\lg$ & o Bife de maminha. \\
\hline Pimenta do reino & $0,5 \mathrm{~g}$ & $0,5 \mathrm{~g}$ & (Grill) por \\
\hline \multicolumn{3}{|c|}{ PORÇÃO = 120 gramas } & $\begin{array}{l}\text { minutos. } \\
\text { Levar o Bife para o prato já } \\
\text { montado. }\end{array}$ \\
\hline
\end{tabular}

\begin{tabular}{lll}
\multicolumn{2}{l}{ VET (per capita) } & $158 \mathrm{kcal}$ \\
CHO & $2 \mathrm{~g}$ & $8 \mathrm{kcal}$ \\
PTN & $20,9 \mathrm{~g}$ & $82,4 \mathrm{kcal}$ \\
LIP & $7 \mathrm{~g}$ & $63 \mathrm{kcal}$ \\
SOD & $436 \mathrm{mg}$ & - \\
FIBRAS & - & -
\end{tabular}


NOME DA PREPARACCÃO: LINGUIÇA TOSCANA

\begin{tabular}{|l|c|c|c|}
\hline \multicolumn{1}{|c|}{ INGREDIENTES } & $\begin{array}{c}\text { Peso } \\
\text { Bruto }\end{array}$ & $\begin{array}{c}\text { Peso } \\
\text { líquido }\end{array}$ & Modo de Preparo \\
\hline Linguiça Toscana & $40 \mathrm{~g}$ & $40 \mathrm{~g}$ & $\begin{array}{l}\text { 1. Colocar a linguiça toscana } \\
\text { na Chair Broiler (Grill) por } \\
\text { aproximadamente } 8 \text { a } 10 \\
\text { minutos. }\end{array}$ \\
\cline { 1 - 2 } & $\begin{array}{l}\text { 2. Levar a linguiça para o } \\
\text { prato já montado. }\end{array}$ \\
\hline
\end{tabular}

$\begin{array}{lll}\text { VET (per capita) } & 499 \mathrm{kcal} \\ \text { CHO } & - & - \\ \text { PTN } & 23,2 \mathrm{~g} & 92,8 \mathrm{kcal} \\ \text { LIP } & 45 \mathrm{~g} & 405 \mathrm{kcal} \\ \text { SOD } & 1593 \mathrm{mg} & - \\ \text { FIBRAS } & - & -\end{array}$


NOME DA PREPARACÃO: FRANGO EMPANADO

\begin{tabular}{|c|c|c|c|}
\hline INGREDIENTES & $\begin{array}{c}\text { Peso } \\
\text { Bruto }\end{array}$ & $\begin{array}{c}\text { Peso } \\
\text { líquido }\end{array}$ & Modo de Preparo \\
\hline Frango empanado & $50 \mathrm{~g}$ & $50 \mathrm{~g}$ & 1. Colocar o frango empanado \\
\hline \multicolumn{3}{|c|}{ PORÇÃO = 100 gramas (2unidades) } & $\begin{array}{l}\text { aproximadamente } 4 \text { a } 6 \\
\text { minutos. } \\
\text { 2. Quando estiver levemente } \\
\text { dourado colocar no prato já } \\
\text { montado. }\end{array}$ \\
\hline
\end{tabular}

\begin{tabular}{lll}
\multicolumn{2}{l}{ VET (per capita) } & $212 \mathrm{kcal}$ \\
CHO & $8,5 \mathrm{~g}$ & $34 \mathrm{kcal}$ \\
PTN & $7,5 \mathrm{~g}$ & $30 \mathrm{kcal}$ \\
LIP & $16 \mathrm{~g}$ & $144 \mathrm{kcal}$ \\
SOD & $386 \mathrm{mg}$ & - \\
FIBRAS & - & -
\end{tabular}


NOME DA PREPARAĈ̃O: STEAK BOVINO

\begin{tabular}{|c|c|c|c|}
\hline INGREDIENTES & $\begin{array}{c}\text { Peso } \\
\text { Bruto }\end{array}$ & $\begin{array}{c}\text { Peso } \\
\text { líquido }\end{array}$ & Modo de Preparo \\
\hline Steak bovino & $100 \mathrm{~g}$ & $100 \mathrm{~g}$ & 1. Colocar o steak bovino na \\
\hline \multicolumn{3}{|c|}{ PORÇÃO = 100 gramas } & $\begin{array}{l}\text { aproximadamente } 6 \text { a } 8 \\
\text { minutos. } \\
\text { Quando estiver levemente } \\
\text { dourado colocar no prato já } \\
\text { montado. }\end{array}$ \\
\hline
\end{tabular}

$\begin{array}{lll}\text { VET (per capita) } & 240 \mathrm{kcal} \\ \text { CHO } & - & - \\ \text { PTN } & 19 \mathrm{~g} & 76 \mathrm{kcal} \\ \text { LIP } & 18 \mathrm{~g} & 162 \mathrm{kcal} \\ \text { SOD } & 1053 \mathrm{mg} & - \\ \text { FIBRAS } & - & -\end{array}$


NOME DA PREPARAĈ̃O: COSTELA BOVINA

\begin{tabular}{|c|c|c|c|}
\hline INGREDIENTES & $\begin{array}{c}\text { Peso } \\
\text { Bruto }\end{array}$ & $\begin{array}{c}\text { Peso } \\
\text { líquido }\end{array}$ & Modo de Preparo \\
\hline Costela bovina sem osso & $120 \mathrm{~g}$ & $120 \mathrm{~g}$ & \multirow{4}{*}{$\begin{array}{l}\text { 1. Colocar sal e pimenta sobre } \\
\text { a costela bovina. } \\
\text { 2. Coloca-la na Chair Broiler } \\
\text { (Grill) por } \\
\text { aproximadamente } 8 \text { a } 10 \\
\text { minutos. } \\
\text { 3. Levar a costela para o prato } \\
\text { já montado }\end{array}$} \\
\hline Sal & $1 g$ & $1 \mathrm{~g}$ & \\
\hline Pimenta do reino & $0,5 \mathrm{~g}$ & $0,5 \mathrm{~g}$ & \\
\hline \multicolumn{3}{|c|}{ PORÇÃO = 120 gramas } & \\
\hline
\end{tabular}

$\begin{array}{lll}\text { VET (per capita) } & 349 \mathrm{kcal} \\ \text { CHO } & - & - \\ \text { PTN } & 16,7 \mathrm{~g} & 66,8 \mathrm{kcal} \\ \text { LIP } & 31 \mathrm{~g} & 279 \mathrm{kcal} \\ \text { SOD } & 469 \mathrm{mg} & - \\ \text { FIBRAS } & - & -\end{array}$


NOME DA PREPARAC̄̃̃O: CUPIM

\begin{tabular}{|c|c|c|c|}
\hline INGREDIENTES & $\begin{array}{c}\text { Peso } \\
\text { Bruto }\end{array}$ & $\begin{array}{c}\text { Peso } \\
\text { líquido }\end{array}$ & Modo de Preparo \\
\hline Cupim & $120 \mathrm{~g}$ & $120 \mathrm{~g}$ & \multirow{4}{*}{$\begin{array}{l}\text { 1. Colocar sal e pimenta sobre } \\
\text { o cupim. } \\
\text { 2. Coloca-lo na Chair Broiler } \\
\text { (Grill) } \\
\text { aproximadamente } 7 \text { a } 9 \\
\text { minutos. } \\
\text { 3. Levar o cupim para o prato } \\
\text { já montado }\end{array}$} \\
\hline Sal & $1 \mathrm{~g}$ & $1 \mathrm{~g}$ & \\
\hline Pimenta do reino & $0,5 \mathrm{~g}$ & $0,5 \mathrm{~g}$ & \\
\hline \multicolumn{3}{|c|}{ PORÇÃO = 120 gramas } & \\
\hline
\end{tabular}

\begin{tabular}{lll}
\multicolumn{2}{l}{ VET (per capita) } & $297 \mathrm{kcal}$ \\
CHO & - & - \\
PTN & $19,5 \mathrm{~g}$ & $78 \mathrm{kcal}$ \\
LIP & $24 \mathrm{~g}$ & $216 \mathrm{kcal}$ \\
SOD & $446 \mathrm{mg}$ & - \\
FIBRAS & - & -
\end{tabular}


NOME DA PREPARAĈ̃O: FILÉ DE FRANGO SASSAMI

\begin{tabular}{|c|c|c|c|}
\hline INGREDIENTES & $\begin{array}{c}\text { Peso } \\
\text { Bruto }\end{array}$ & $\begin{array}{c}\text { Peso } \\
\text { líquido }\end{array}$ & Modo de Preparo \\
\hline Filé de frango sassami & $120 \mathrm{~g}$ & $120 \mathrm{~g}$ & \multirow{4}{*}{$\begin{array}{l}\text { 1. Colocar sal e pimenta sobre } \\
\text { o frango. } \\
\text { 2. Coloca-lo na Chair Broiler } \\
\text { (Grill) } \\
\text { aproximadamente } \\
\text { minutos. } \\
\text { 3. Levar o frango para o prato } \\
\text { já montado. }\end{array}$} \\
\hline Sal & $1 \mathrm{~g}$ & $1 \mathrm{~g}$ & \\
\hline Pimenta do reino & $0,5 \mathrm{~g}$ & $0,5 \mathrm{~g}$ & \\
\hline \multicolumn{3}{|c|}{ PORÇÃO = 120 gramas } & \\
\hline
\end{tabular}

\begin{tabular}{lll}
\multicolumn{2}{l}{ VET (per capita) } & $140 \mathrm{kcal}$ \\
CHO & - & - \\
PTN & $19 \mathrm{~g}$ & $76 \mathrm{kcal}$ \\
LIP & $6,9 \mathrm{~g}$ & $62,1 \mathrm{kcal}$ \\
SOD & $384 \mathrm{mg}$ & - \\
FIBRAS & - & -
\end{tabular}

